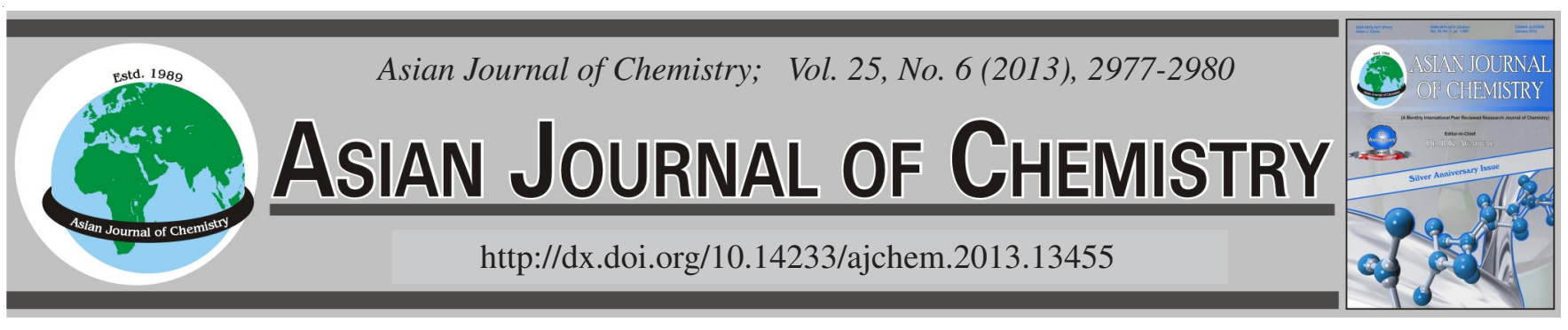

\title{
Accumulation of Copper and Lead in Selected Medicinal Plants
}

\section{S. SHAVAKH ${ }^{1}$, S. GHALANDARI KAVKANI ${ }^{1, *}$ and J. NOURI ${ }^{2}$}

${ }^{1}$ Department of Plant Protection, School Faculty of Agriculture and Natural Resources, Science and Research Branch, Islamic Azad University, Tehran, Iran

${ }^{2}$ Department of Environmental Management, Graduate School of the Environment and Energy, Science and Research Branch, Islamic Azad University, Tehran, Iran

*Corresponding author: E-mail: s_ghalandary@yahoo.com

(Received: 16 January 2012;

Accepted: 5 December 2012)

AJC-12500

\begin{abstract}
The present study aims to estimate lead and copper metals content in four medicinal plants collected from different sites of Saveh region located in south western of Tehran, in June and August 2010. Samples of Eucalyptus globules, Mentha piperita, Thymus vulgaris and Rosa damascena were separately collected from different locations and prepared in laboratory. Lead and copper content were measured in each samples using atomic absorption spectrophotometry. Results show that lead content was the highest in Mentha piperita and the lowest was in T. vulgaris. However, T. vulgaris and E. globulus contained the highest and the lowest levels of copper, respectively. Overall, despite of vital advantages of studied medicinal plants, heavy metals contamination prevent of therapeutic uses of these plants which may result in fatal effects on human health.
\end{abstract}

Key Words: Metal pollution, Eucalyptus globules, Mentha piperita, Thymus vulgaris, Rosa damascene.

\section{INTRODUCTION}

During past decades, the use of medicinal plants in agronomy productions, dietary supplements, pharmacy, as well as therapeutic purposes has been achieved with increasing interest worldwide ${ }^{1-4}$. In this regard, herbal medicine has also played a crucial role in the pharmaceutical and health markets of 21 st century ${ }^{5}$. So that, growing interest of developing, as well as developed countries towards cultivation of medicinal and aromatic plants has augmented rapidly ${ }^{6,7}$. However, there have been also reported some cases of illness and fatalities induced by use of such plants ${ }^{8,9}$. Poisoning of toxic metals, contained in medicinal plants through soil, water or air, were reported in the United States, Europe and Asian countries, as well ${ }^{10-13}$. In addition, there exist some major reasons for presence of toxic metals in medicinal plants, including growth in polluted areas, use of agricultural expedients (such as cadmium-containing fertilizers, organic mercury or lead based pesticides); contaminated irrigation water ${ }^{14-17}$. Accumulation of metals can occur in both root and above-ground organs deduced to transfer toxic metals into food chain ${ }^{18}$. So, several harmful effects on animal and human health, such as nephrotoxicity which induce abnormalities of tublar re-absorption are as the consequences ${ }^{19}$. Moreover, renal and nervous system would be attacked by the adverse effects of lead and mercury ${ }^{20,21}$. For instance, copper facilitates Glucose oxidation and energy release consequently. Iron absorption, oxygen supplement for tissues particularly brain tissues and brain function improve by higher level of copper in body. Copper level is relatively related to estrogen level. Shortage of copper deduced to anemia, depression and dermal problems. However, high adsorption of copper leads to headache and hypoglycemia. Moreover, additional copper content is deposited in brain and liver which damage livers and result in anemia and alopecia in women. Besides, lead is a naturally-occurring element which might be harmful to humans, especially children, if ingested or inhaled higher. Lead poisoning can cause a number of adverse human health effects, but is particularly detrimental to the neurological development of children. In this regard, monitoring of heavy metals contained in medicinal plants is of great priority ${ }^{22}$ for two essential reasons: first, increasing trend of general environment contamination by toxic metals ${ }^{23}$, second, toxic contains of heavy metals and/or arsenic content in exotic herbal remedies. The present study aims to determine the amounts of copper and lead in four selected medicinal plants, including Eucalyptus globules, Mentha piperita, Thymus vulgaris and Rosa damascena. This research has been performed in Science and Research Branch, Islamic Azad University, Tehran, during 2010-2011. 


\section{EXPERIMENTAL}

Sampling of Eucalyptus globules, Mentha piperita, Thymus vulgaris and Rosa damascena were performed randomly in June and August 2010 throughout the Saveh region located in south western of Tehran, Iran (Fig. 1). The samples were firstly rinsed with distilled deionized water and then air dried in the laboratory condition. Then, each sample was milled separately in a micro-hammer (without metal in it) and $2 \mathrm{~g}$ of powdered sampled plants were poured in Erlenmeyer adding $20 \mathrm{~mL}$ $\mathrm{HNO}_{3}$. Digesting the composed samples on a hot plate exposure to a low temperature $\left(40{ }^{\circ} \mathrm{C}\right), 20 \mathrm{~mL} \mathrm{HNO}_{3} 2 \mathrm{~N}$ has been added and the total volume reached to $50 \mathrm{~mL}$. The sample was then vacuum-filtered through Whatman 42 filter paper. Afterwards, by Atomic absorption spectrophotometry 200; varian; made in USA. Accumulation level of $\mathrm{Cu}$ and $\mathrm{Pb}$ were measured and shown in standard curves and graphs.

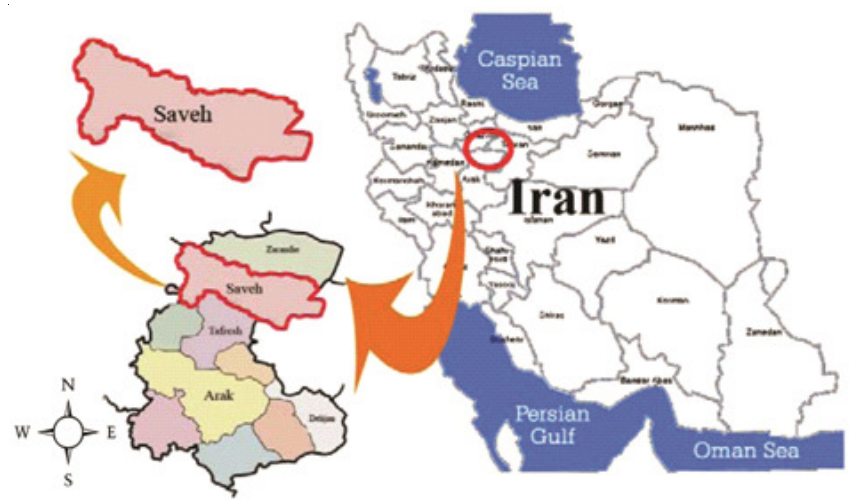

Fig. 1. Location of the study area

Table-1 shows the studied medicinal plants specifying therapeutically usable parts of them for the present study.

\begin{tabular}{ccc}
\multicolumn{3}{c}{ TABLE-1 } \\
\multicolumn{3}{c}{ SCIENTIFIC TITLES OF SAMPLED PLANTS } \\
\multicolumn{2}{c}{ SPECIFYING THERAPEUTICALLY USABLE PARTS } \\
\hline Sample code & Family & Scientific name \\
\hline $\mathrm{a}$ & Myrtaceae & Eucalyptus globulus \\
$\mathrm{b}$ & Lamiaceae & Mentha piperita \\
$\mathrm{c}$ & Lamiaceae & Thymus vulgaris \\
$\mathrm{d}$ & Rosaceae & Rosa damascena \\
\hline \multicolumn{3}{c}{} \\
\hline \multicolumn{3}{l}{ RESULTS AND DISCUSSION }
\end{tabular}

Heavy metals concentrations were investigated in four selected medicinal plants and results are shown in Figs. 2 and 3 . analyzing two elements $(\mathrm{Cu}$ and $\mathrm{Pb})$, metal contents were in order of below: Pb content: Mentha piperita $>$ Eucalyptus globulus > Rosa damascena > Thymus vulgaris. Cu content: Thymus vulgaris $>$ Rosa damascena $>$ Mentha piperita $>$ Eucalyptus globulus, confirmed that the heavy metals contents in plants depending on the country of origin,environmenal pollution levels, plant part and technological processes.

Lead: Lead is the most toxic environmental pollutant the main sources of lead pollution in agriculture and plants are lead mines, fuel combustion, sewage sludge applications and farmyard manure ${ }^{24}$. It reacts or complexes with many biomolecules and adversely affects the reproductive, nervous, gastrointestinal, immune, renal, cardiovascular, skeletal and muscular systems as well as developmental processes ${ }^{25}$ suggest that lead levels are generally higher in leaves than in other plant parts probably because lead contaminations occur mainly through the atmosphere whereas lead uptake capacity of plants is generally low ${ }^{26}$.

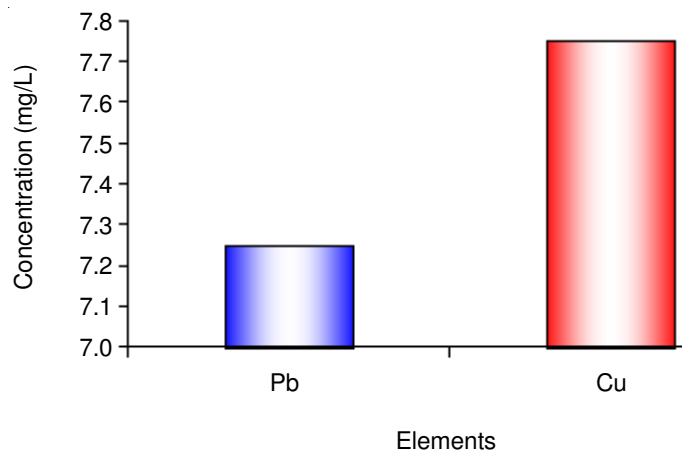

(a)

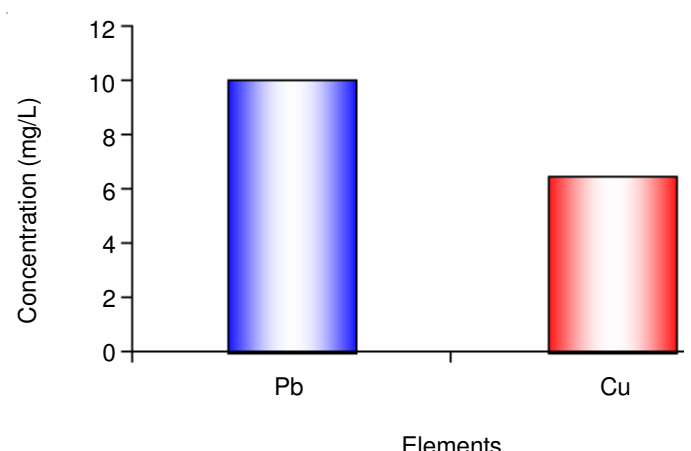

(b)

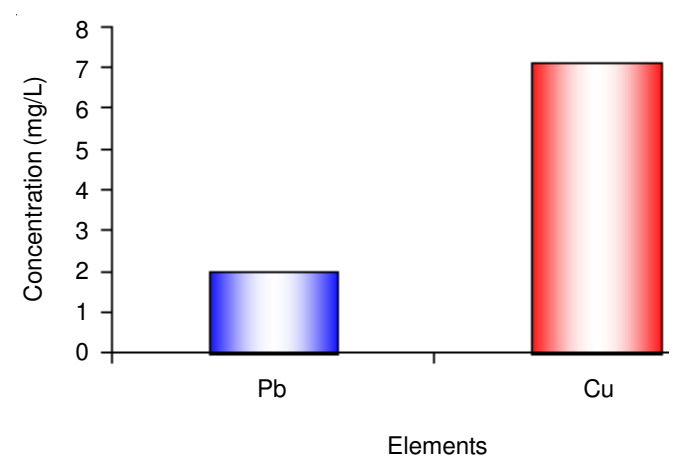

(c)

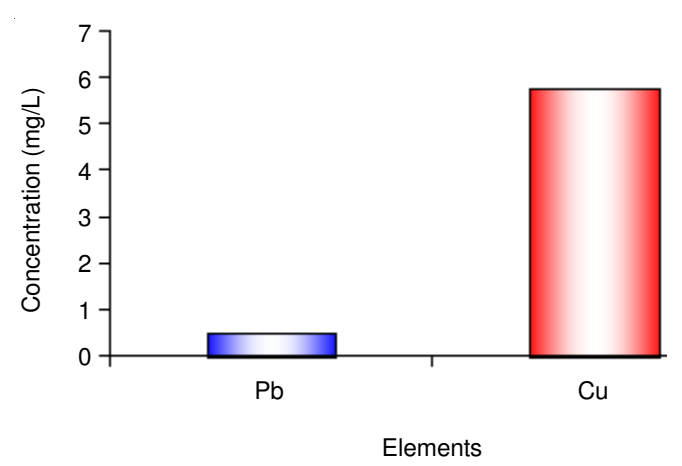

(d)

Fig. 2. $\mathrm{Pb}$ and $\mathrm{Cu}$ values in selected plants in 1 st step 


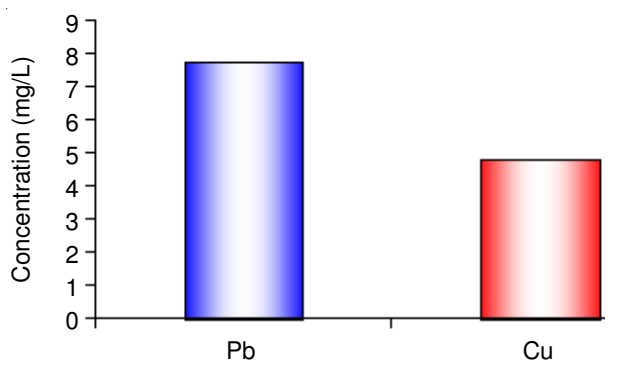

(a)

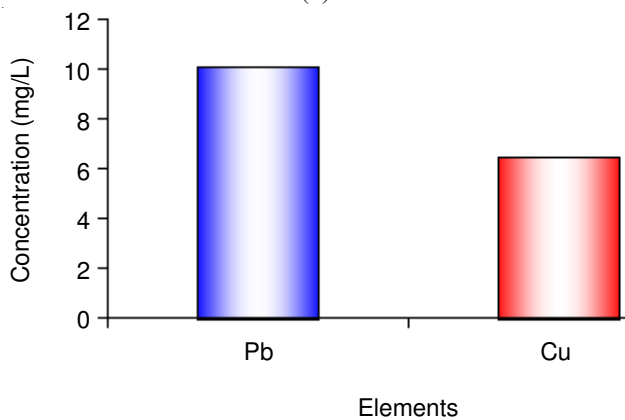

(b)

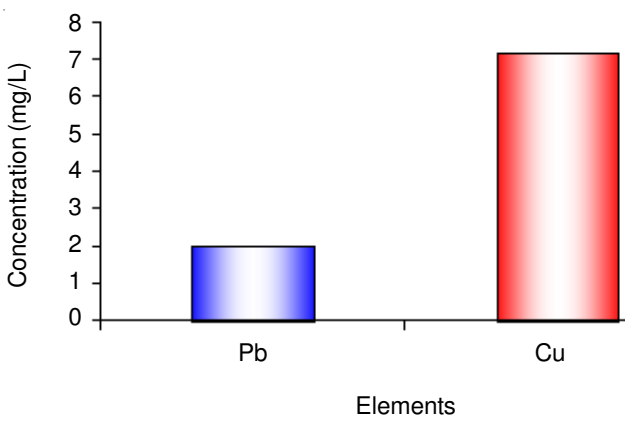

(c)

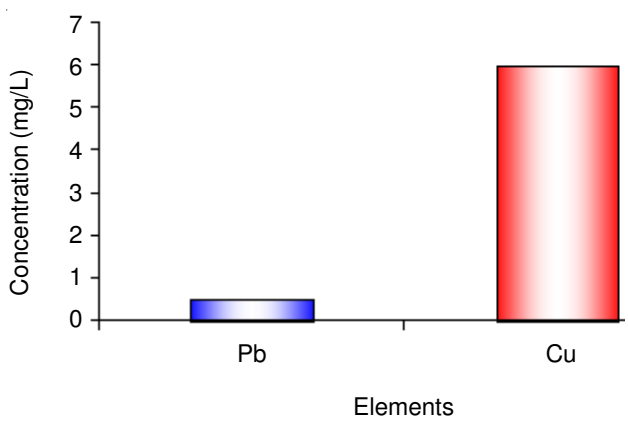

(d)

Fig. 3. $\mathrm{Pb}$ and $\mathrm{Cu}$ values in selected plants in 2 nd step

Copper: Copper plays a role in the oxidative defense system, on the other hand chronic cu toxicity can results in severe poisoning, oxidative stress and human health ${ }^{27}$. Copper is considered as a micronutrient for plants ${ }^{28}, \mathrm{Cu}$ is also an essential component of various proteins like plastocyanin of photosynthetic system and cytochrome oxidase of respiratory electron transport chain ${ }^{29}$. But enhanced industrial and mining activities have contributed to the increasing occurrence of $\mathrm{Cu}$ in ecosystems. Although copper is an essential enzymatic element for normal plant growth and development but can be toxic at excessive levels. Phytotoxicity can occur if its concen- tration in plants is higher than $20 \mathrm{mglkg} \mathrm{DW}$ (dry weight). Critical concentration for copper in plants is $20-100 \mathrm{mg} / \mathrm{kg}^{30}$. Overall, therapeutic properties of the two latter plants are of high importance, due to $\mathrm{Cu}$ content as a harmful element for human health, they are not suggested for consumption.

Throughout the conducted investigation, copper and lead level were measured consecutively and tabulated in Tables 2 and 3. According to the results, lead level in Eucalyptus globulus, as well as Mentha piperita was higher than copper. However, Thymus vulgaris and Rosa damascena contained more copper rather than lead.

\begin{tabular}{ccc}
\multicolumn{4}{c}{ TABLE-2 } \\
CONSECUTIVE MEASUREMENTS OF LEAD $(\mathrm{mg} / \mathrm{L})$ \\
\hline Sample & Conc. $(\mathrm{mg} / \mathrm{L})$ & $\mathrm{RSD}(\%)$ \\
\hline \multicolumn{4}{c}{ Phase 1} \\
$\mathrm{a}$ & 0.290 & 2.2 \\
$\mathrm{~b}$ & 0.400 & 1.1 \\
$\mathrm{c}$ & 0.080 & 36.5 \\
$\mathrm{~d}$ & 0.020 & $>100$ \\
\hline & Phase 2 & - \\
\hline $\mathrm{a}$ & 0.310 & - \\
$\mathrm{b}$ & 0.404 & - \\
$\mathrm{c}$ & 0.082 & - \\
$\mathrm{d}$ & 0.021 &
\end{tabular}

TABLE-3

CONSECUTIVE MEASUREMENTS OF COPPER (mg/L)

\begin{tabular}{ccc}
\hline Sample & Conc. $(\mathrm{mg} / \mathrm{L})$ & RSD $(\%)$ \\
\hline \multicolumn{3}{c}{ Phase 1 } \\
\hline a & 0.190 & 0.6 \\
b & 0.260 & 0.8 \\
c & 0.286 & 0.3 \\
d & 0.230 & 0.9 \\
\hline \multicolumn{4}{c}{ Phase 2 } \\
b & 0.195 & - \\
c & 0.263 & - \\
d & 0.290 & - \\
\hline
\end{tabular}

RSD: Relative standard deviation.

\section{Conclusion}

Medicinal plants gained an important role in different pharmaceutical as well as therapeutic purposes during last decades. However, accumulation of heavy metals in these plants induces more attention before using them for remedies diseases. Therefore, it is essential to monitor the heavy metals content if such plants are meant for human consumption. Further studies are recommended for heavy metal contents of medicinal plants. The content of toxic metals in plant spices and herbs was found to be generally low. The highest contents of cooper was shown in Eucalyptus globules, the highest contents of lead was shown in Mentha piperita.

\section{ACKNOWLEDGEMENTS}

The authors thank Mr. A.R. Soltanabadi and S. Salehi for useful corporation throughout the progress of this work and the Science and Research Branch, the Laboratories Complex for its support throughout the analytical experiments. 


\section{REFERENCES}

1. P.W. Wood, Essence, 30, 42 (1999)

2. I.A. Khan, J. Allgood, L.A. Walker, E.A. Abourashed, D. Schelenk and W.H. Benson, J. AOAC Int., 84, 936 (2001).

3. WHO, Drug Information, Herbal Medicines, World Health Organization, Geneva, Vol. 16 (2002).

4. H. Krug, Gemuseproduktion Paul Parey, Cited from Chizzola, R. Metallic Trace Elements in Herbs and Spices Grown in Austria Acta Hortic, p. 249 (1986).

5. H.E. Kleinschmidt and R.W. Johnson, Weeds of Queensland, Queensland Department of Primary Ind., Australia, p. 147 (1977).

6. E. Liu and Y.J. Zheng, Asian J. Chem., 23, 1091 (2011).

7. J. Nouri, B. Lorestani, N. Yousefi, N. Khorasani, A.H. Hasani, F. Seif and M. Cheraghi, Environ. Earth Sci., 62, 639 (2011).

8. M.J. Stewart, J.J. Moar, P. Steenkamp and M. Steenkamp, Forensic Sci. Int., 101, 177 (1999).

9. E. Ernst, Pharmacol. Sci., 23, 136 (2002).

10. A. Olujohungbe, P.A. Fields and A.F. Sanford, Postgraduate Med. J., 70, 764 (1994)

11. D.W. Dunbabin, G.A. Tallis and P.Y. Popplewell, Med. J. Aust., 157, 835 (1992).

12. T. Kaksoy, A. Hudak and M. Naray, J. Toxicol.-Clin. Toxicol., 34, 507 (1996).

13. S.B. Markowitz, C.M. Nenez and J.M. Clark, Fields Crops Res., 60, 143 (1999)

14. C.M.D. Levitt, J. Am. Med. Assoc., 252, 3127 (1984).

15. T.Y.K. Chan, B. Tomlinson and A.J.H. Critchley, Lancet, 342, 1532 (1993).
16. E. Pip, Bull. Environ. Contam. Toxicol., 46, 790 (1991).

17. A.A.K. Abou-Arab, M.S. Kawther, M.E. El Tantawy, R.I. Badeaa and N. Khayria, Food Chem., 67, 357 (1999).

18. A. Kabata-Pendias and H. Pendias, Trace Elements in Soils and Plants, CRC Press Inc, Boca Raton, Florida, USA, edn. 2 (1992).

19. G. Nordberg, Toxicol. Pharmacol., 30, S57 (1999).

20. S. Tong, Y.E. von Schirnding and T. Prapamontol, Bull. World Health Organization, 78, 1068 (2000).

21. WHO, Elemental Mercury and Inorganic Mercury Compounds: Human Health Aspects, Concise International Chemical Assessment Document 50, World Health Organization, Geneva (2003).

22. P.A.G.M. De Smet, Adverse Effects of Herbal Drugs; Springer-Verlag Berlin; ISBN 3-540-53100-9 (1992).

23. S.L. Ali, Pharm. Ind., 45, 1294 (1983).

24. M.A. Khan, I. Ahmad and Inayat-ur-Rahman, J. Chin. Chem. Soc., 54, 339 (2007)

25. F.M. Johnson, Mut. Res., 410, 123 (1998).

26. A.A. Abou-Arab and M.A.A. Donia, J. Agric. Food Chem., 48, 2300 (2000).

27. J.Y. Uriu-Adams and K.C.L. Copper, Mol. Aspects Med., 26, 268 (2005).

28. F. Thomas, C. Malick, E.C. Endreszl and K.S. Davies, Physiol. Plant., 102, 360 (1998).

29. K. Demirevska-Kepova, L. Simova-Stoilova, Z. Stoyanova, R. Holzer and U. Feller, Environ. Exp. Botany, 52, 253 (2004).

30. U. Gupta, In ed.: J.O. Nariago, Copper in the Environment, John Wiley \& Sons, New York, p. 255 (1975). 